\title{
A mirada da biotipologia no Sul do Brasil: discurso e prática nas décadas de 1930 e 1950
}

\author{
The view of biotypology in Southern Brazil: discourse and \\ practice in the 1930s and 1950 s
}

\section{Renilson Beraldo}

Assistente de pesquisa, Fiotec/ Fiocruz.

Avenida Brasil, 4365

21040-361 - Rio de Janeiro - RJ - Brasil

beraldo_rfs@hotmail.com
BERALDO, Renilson. A mirada da biotipologia no Sul do Brasil: discurso e prática nas décadas de 1930 e 1950. História, Ciências, Saúde-Manguinhos, Rio de Janeiro, v.23, supl., dez. 2016, p.235-241.

Resumo

Esta nota de pesquisa tenta demonstrar como o estado do Paraná figurou no panorama transnacional das vertentes de escolas biotipológicas presentes no Brasil a partir dos anos 1930. Abordamos o caso específico da cidade de Curitiba e pudemos identificar, num discurso acadêmico de 1938 e em dois laudos de sanidade mental de 1950 e 1951, a regularidade da escola constitucionalista alemã de Ernst Kretschmer, não obstante a preponderância da vertente italiana na bibliografia relacionada ao tema. Com isso, procuramos apontar por quais meios e espaços foram legitimados os preceitos concernentes àquela escola.

Palavras-chave: biotipologia; Curitiba; Paraná (estado); escola constitucionalista alemã; Ernst Kretschmer (1888-1964).

\section{Abstract}

This research report aims to demonstrate how the state of Paraná, Brazil, featured in the transnational context of different schools of biotypological thought present in Brazil as of the 1930s. The city of Curitiba is taken as a case study, where we can identify, in an academic lecture from 1938 and two mental health reports from 1950 and 1951, the observance of Ernst Kretschmer's German constitutional medicine, despite the prevalence of the Italian school of thought in the bibliography on the subject. With this, we seek to identify through what channels and forums the precepts of the German school were legitimized.

Keywords: biotypology; Curitiba; Paraná (state); German constitutional medicine; Ernst Kretschmer (1888-1964). 
A presente nota é uma reflexão em torno dos desenvolvimentos de minha pesquisa de mestrado. Seu objetivo foi analisar a atuação de um grupo de médicos envolvido com as matérias e temáticas da neurologia, medicina legal e psiquiatria, intentando perceber como esse grupo figurou no processo de institucionalização da medicina por intermédio da Associação Médica do Paraná (AMP) entre 1930 e 1941 (Beraldo, 2016). Essa instituição é o órgão representativo da classe médica paranaense desde 1933, quando a categoria médica, alocada na cidade de Curitiba, capital paranaense, protagonizou a fusão de três agremiações que a representavam, a saber: Sociedade de Medicina do Paraná (1914), Sociedade Médica dos Hospitais do Paraná (1930) e Sindicato Médico do Paraná (1931) (Siqueira, 1993, p.23). Consideramos esse recorte e esse objetivo relevantes, e com base neles pretendemos dar uma contribuição à história da medicina paranaense e, particularmente, à historiografia sobre neurologia, medicina legal e psiquiatria a partir daquele grupo de médicos agremiados nos anos 1930. Para fazê-lo, temos optado por uma documentação que inclui as "atas de sessões" da AMP, "noticiários", "conferências" e "artigos" publicados nas páginas da Revista Médica do Paraná (RMP), criada em 1931, bem como em bibliografia memorialística mapeada até o momento (Siqueira, 1993; Alves, Pilotto, 1994; Costa, Lima, 2007; Wittig, 2011).

Dito isso, nosso objetivo nesta nota, embora restrito, será apresentar alguns achados expressivos a respeito da interlocução entre prática psiquiátrica na cidade de Curitiba e a escola biotipológica constitucionalista de vertente alemã, a qual teve na figura de Ernst Kretschmer (1888-1964) seu articulador e principal correspondente. Será analisado o discurso "A ciência psiquiátrica, seu mérito, sua evolução e suas conquistas no terreno da clínica e da terapêutica", proferido pelo médico Alô Ticoulat Guimarães em 1938 na Faculdade de Medicina do Paraná (FMP), fundada em 1913, e publicado na RMP. Posteriormente, tentaremos perceber como os parâmetros que orientavam a prática daquele médico apareceram em dois laudos de sanidade mental aqui inseridos.

Referir-se à biotipologia como campo biomédico, é importante dizer, implica tanto observá-la como "uma aplicação 'prática' da eugenia galtoniana" (Vallejo, 2004, p.220) quanto atentar para a relevância contextual de suas expressões complexas e singulares. Circunstâncias nacionais, políticas e culturais possibilitaram o florescimento de diferentes "escolas de biotipologia" (Eraso, 2007, p.794). Assim, poderíamos constatar, na Itália, por exemplo, como foi encampada a criação de institutos de biotipologia para vigilância, valoração e melhora de corpo e mente de coletividades, dos quais o Instituto Biotipológico e Ortogenético de Gênova é um importante exemplo (Vallejo, 2004, p.222-223); no México, ao observá-la como instrumento voltado para uma nova forma de diagnóstico e uma "teoria da diferenciação humana" (Stern, 2003, p.197); ou na Argentina e sua relação com controle demográfico e populacional (Miranda, 2005, p.191); e, finalmente, no Brasil, num contexto de busca de definições identitárias nacionais, a manifestação daquele campo como auxílio aos "esforços de classificação e definição de uma característica corporal própria dos brasileiros" (Vimieiro-Gomes, 2012, p.706). 


\section{Alô Ticoulat Guimarães e a "escola alemã" de biotipologia}

No que se refere ao Brasil, a biotipologia teve diversas entradas e adaptações locais, embora figure na bibliografia a preponderância da escola de vertente italiana, representada por personagens como Nicola Pende, Mario Barbàra e Giacinto Viola. Esses médicos são atores centrais para pensar a articulação da biotipologia de vertente italiana e tiveram crédito atestado entre fomentadores brasileiros, como Waldemar Berardinelli, Juvenil Rocha Vaz e Isaac Brow (Vimieiro-Gomes, 2012, p.709-711). De minha parte, entretanto, procuro demonstrar como a escola de tendência alemã, com sua guinada psicológica e orientada por Ernst Kretschmer, ${ }^{1}$ figurou na prática médica em uma localidade do Sul do Brasil, na cidade de Curitiba, estado do Paraná. Vejamos.

Alô Ticoulat Guimarães (1903-1985), ${ }^{2}$ natural de Curitiba, médico formado pela FMP, defendeu, em 1927, a tese Cirrose atrófica de Laennec combinada com mal de Banti. Passou a fazer parte do corpo clínico do Hospício Nossa Senhora da Luz, fundado em 1903, logo após sua formatura. Na carreira desse médico conectaram-se ensino e prática médico-legal e clínica psiquiátrica, sendo livre-docente daquela em 1935 e primeiro professor desta em 1936 (Alves, Pilotto, 1994, p.54; Ouyama, 2006; Lima, Holanda, 2011; Wadi, 2012). Dois anos após a conquista da cátedra, no dia 7 de março de 1938, seu discurso "A ciência psiquiátrica..." externava para a plateia quais parâmetros orientavam sua prática médica. De um lado, a importância dos tratamentos biológicos como malarioterapia e insulinoterapia, de outro, as possibilidades diagnósticas da escola constitucionalista de Kretschmer (Guimarães, 1938, p.105).

Uma das preocupações de Alô T. Guimarães foi demonstrar, principalmente para médicos clínicos e cirurgiões da plateia, como a "ciência psiquiátrica" deveria ser colocada em pé de igualdade com a medicina em geral. Sua intenção era desmitificar a crença que separava, de um lado, os "trunfos do método experimental" no terreno da clínica médico-cirúrgica e, de outro, a "falível autoridade científica" e os "pouco convincentes índices de sua argumentação". Para fazê-lo, igualou a "patologia mental" e a "patologia geral" quanto a suas origens, seus propósitos e desdobramentos (Guimarães, 1938, p.105-107). O que está subjacente é uma narrativa da psiquiatria em termos de evolução e melhoramento à medida que identifica o desenvolvimento das psicopatias, partindo de Hipócrates, até a nosografia psiquiátrica da escola organicista de Emil Kraepelin, passando por Pinel, Bayle, Morel e Magnan.

"Como se afirmam e corporificam o mérito, a extensão e as finalidades da ciência psiquiátrica?" - perguntava-se o médico na ocasião (Guimarães, 1938, p.107). E respondia positivando elementos laboratoriais responsáveis pela "pesquisa e experimentação anatomofisiológica" (reações no liquor e no sangue) e também por meio da observação das desordens endócrinas, da medição e extensão das lesões com o auxílio da encefalografia (p.109). Foi, entretanto, a respeito do tema "constituição" e "caráter" que aquele médico mais mobilizou autores, exemplos e demonstrações, e, com isso, gostaria de destacar que as teorias constitucionalistas lançaram mão de aportes da ciência experimental para mensurar "aspectos morfológicos, fisiológicos (sobretudo, dialogando com a endocrinologia) e psicológicos, por vezes tidos como de base hereditária", e sua soma é o que se convencionou chamar de constituição (Vimieiro-Gomes, 2012, p.707). 
Pautando-se em Robert Gaupp (psiquiatra alemão e mestre de Kretschmer), Alô T. Guimarães fez a seguinte leitura da obra de Kretschmer: as tendências organicistas e psicológicas da psiquiatria moderna não teriam dado respostas à questão constitucional e temperamental, mesmo admitindo as contribuições de Kraepelin à compreensão das doenças endógenas. Tais questões, contudo, estacariam no tema da constituição e temperamento (Guimarães, 1938, p.110-111). É importante ressaltar que, no plano das constituições, tudo se passa como uma questão de "correspondência": formas exteriores do corpo relacionam-se à personalidade humana; as doenças relacionam-se às constituições morfológicas e aos temperamentos; e, mais, aos tipos psiquiátricos corresponderiam os tipos corporais. Por essa feita, a escola constitucionalista, afirmava Alô T. Guimarães citando o psiquiatra espanhol Antonio VallejoNágera, pretendia "nos explicar a variabilidade existente de um indivíduo a outro em relação ao meio e, por conseguinte, a distinta aptidão individual para contrair a doença" (p.112). Analisando corpo e mente, constitucionalistas buscaram focar e entender "o indivíduo por trás da doença" (Eraso, 2007, p.794).

\section{"Não há doenças, sim doentes"}

Em sua prática clínica, Alô T. Guimarães testou o modelo de configuração corporal de Kretschmer em indivíduos criminosos enviados à cidade de Curitiba para ser submetidos a exames de sanidade mental. Mais de dez anos depois de sua conferência de abertura do ano letivo de 1938, encontramos, já na década de 1950, a permanência de categorias utilizadas por aquele médico e seus assistentes para descrever a morfologia corporal de indivíduos. Seguem dois casos mapeados: (a) no dia 22 de agosto de 1950 compareceu à subdelegacia do distrito de Pinhão (PR) a senhora G.A.S., com 38 anos de idade, brasileira, doméstica, natural daquele estado, casada religiosamente e analfabeta. Estava sendo acusada de agredir gravemente seu marido com uma foice (Cedoc/G, 1950, fls.2-8); (b) no dia 5 de fevereiro de 1951 compareceu à subdelegacia do distrito de Pedro Lustosa o senhor G.F.R., com 37 anos, brasileiro, lavrador, acusado de crime de parricídio (Cedoc/G, 1951, fls.10-11).

Ambos os depoimentos apresentaram-se inconclusivos na época, e seus advogados acionaram a necessidade de intervenção médica. Ambos foram enviados à cidade de Curitiba e passaram pelo crivo de Alô T. Guimarães. No primeiro laudo de sanidade, constatamos o seguinte: "indivíduo de constituição fraca, panículo adiposo escasso, musculatura pouco desenvolvida, de estatura mediana, pertencente por seu aspecto morfológico ao tipo leptossômico da classificação de Kretschmer" (Cedoc/G, 1950, s.p.). No entender de Berardinelli, esses seriam indivíduos com tendência a desenvolver esquizofrenia (citado por Vimieiro-Gomes, 2012, p.710). Do segundo laudo, constou: "é o examinado de constituição forte, estatura mediana, panículo adiposo irregularmente distribuído, musculatura bem desenvolvida, pertencendo por sua conformação biotipológica ao pícnicodisplásico da classificação de Kretschmer" (Cedoc/G, 1951, fls.37-38). Seriam indivíduos baixos e com desproporção dos membros e tendências à maníaco-depressão. Kretschmer reconhecia dois tipos psicológicos básicos: circular e esquizofrênico. Pensou as personalidades circulares dentro de três grupos de características: (1) sociável, bem-humorado, amigável, genial; (2) alegre, bem-humorado, apressado; e (3) tranquilo, calmo, facilmente deprimido, coração mole. 
O primeiro grupo foi considerado o mais comum. Os tipos de personalidade esquizofrênica também se dividiriam em três grupos de características: (1) antissocial, silencioso, reservado, sério, (sem graça), excêntrico; (2) acanhado, tímido, sentimentos finos, sensível, nervoso, excitável, amante da natureza e de livros; e (3) flexível, gentil, honesto, indiferente, obtuso, em silêncio. ${ }^{3}$

Ambos os casos citados foram internados no hospício e lá faleceram. Não há como descartar o efeito do diagnóstico dado por aqueles médicos. Nesse caso, a justiça orientou-se por um prognóstico, no qual Alô T. Guimarães qualificava o quinhão da constitucionalogia e caracterologia: "contribuem com os elementos decisivos para a feitura do diagnóstico e, principalmente, para a ampliação e certeza das avaliações prognósticas" (Guimarães, 1938, p.114). Tal posicionamento dava aval ao dito "não há doenças, sim doentes" repetido pelo médico e atribuído a Juvenil Rocha Vaz, responsável pela cadeira de clínica propedêutica na Faculdade de Medicina do Rio de Janeiro (FMRJ), onde funcionava um Gabinete Biotipológico.

\section{Considerações finais}

A análise da composição da população brasileira, em particular a paranaense, pode ser observada em trabalhos produzidos a partir da década de 1930 no âmbito de serviços (Serviço do Prof. Rocha Vaz, FMRJ), gabinetes ou instituições assistenciais, como é o caso do espaço em que Alô T. Guimarães atuava, o Hospício Nossa Senhora da Luz. De um lado, uma obra intitulada Antropologia do brasileiro do interior paranaense foi escrita na década de 1940 por Augusto Sette Ramalho (citado em Vimieiro-Gomes, 2012, p.716) e se prestava a analisar os corpos de inscritos para o serviço do Exército, de outro, numerosos laudos de sanidade mental, conferências e trocas científicas foram professados por personalidades médicas no âmbito de instituições e agremiações médico-científicas, como a que é objeto desta pesquisa. Constituíram-se em espaços e meios de afirmação daqueles saberes.

Duas conclusões parciais podem ser aqui registradas. Primeiro: conquanto suas singularidades, a evidência de um repertório transnacional de teorias científicas e métodos, identificado por Stern (2003) para sua análise sobre o México, é expressiva no que concerne ao Brasil no diálogo com as escolas italiana, francesa e alemã entre as décadas de 1930-1950 (Vimieiro-Gomes, 2012, p.709-711). O caso do Paraná aqui analisado compõe um modesto capítulo a respeito da adaptação local da biotipologia em sua vertente alemã. As perspectivas se abrem quando pensamos nesse campo biomédico como modalidade ou detentor de um sentido prático para a eugenia (Vallejo, Miranda, 2004, p.231). É possível supor que em torno de Alô T. Guimarães constituiu-se uma tradição de classificação e correspondência com as escolas biotipológicas, uma geração que abarcava professores, alunos, assistentes e colegas de trabalho, como José Schetinni, Levi Miró Carneiro e Aramis Taborda de Athayde - este último, ministro da Saúde em 1954. Uma segunda conclusão possível é que, partindo da direção que aqui foi iniciada, uma abordagem mais ampla contribuiria para pensar numa relação transatlântica de ideias e nas "dimensões espaciais de contato" (Rinke, 2014, p.14-15), na permanência, pelos meios aqui explicitados, da correspondência entre Brasil e Alemanha, um caminho para refletir sobre a noção de "distância" no período entre as duas guerras mundiais. 


\section{AGRADECIMENTO}

Sou grato a Grazieli Eurich pela disponibilização da enciclopédia aqui citada - Encyclopedia of criminological theory (Plouffe, 2010). Esse material se encontra disponível na biblioteca da Southern Illinois University (SIU), Carbondale, EUA.

\section{NOTAS}

${ }^{1}$ Ernst Kretschmer estudou medicina nas universidades de Tubingen, Munique e Hamburgo. Atuou como prático de clínica psiquiátrica, especialmente militar. A partir de 1918 lecionou em Tubingen, em 1929 esteve na Universidade de Marburg como professor de psiquiatria e neurologia. Em 1959 se aposentou do cargo de diretor da Clínica Neurológica na Universidade de Tubingen. Sua principal obra, Physique and character, foi publicada em 1921. Nela se podem encontrar as principais ideias de Kretschmer sobre características físicas e psicológicas. São famosos os seus três tipos classificatórios: pícnicos, astênicos e atléticos (Plouffe, 2010).

${ }^{2}$ Ao longo de sua carreira, Alô Ticoulat Guimarães foi eleito duas vezes prefeito da cidade de Curitiba, deputado estadual, senador, vice-presidente da Comissão de Saúde do Senado Federal, foi médico particular de Manuel Ribas (interventor e governador do estado junto ao governo Vargas, entre 1932 e 1945); inserido na mídia jornalística por seu irmão Acir Guimarães, a partir de 1925, mantém uma seção no jornal Gazeta do Povo para responder a perguntas dos leitores. Sua inserção no Hospício Nossa Senhora da Luz foi facilitada pela influência do médico e tio Abdon Petit Guimarães Carneiro (1876-1940), que atuava como clínico naquele hospital (Lima, Holanda, 2011, p.358-359). Cinco anos após seu falecimento, Austregésilo Carrano publicou, em 1990, o livro Canto dos malditos, de caráter biográfico. Carrano narrou sua experiência de violências em instituições psiquiátricas e chamou a atenção para a figura de Alô Guimarães nessa narrativa. Seu relato inspirou o filme Bicho de sete cabeças (2000), dirigido por Laís Bodanzky.

${ }^{3}$ Nessa classificação, os primeiros grupos eram sempre considerados estatisticamente mais comuns. "Deve ser enfatizado que Kretschmer não considerou estes agrupamentos de características como sendo indicadores de saúde ou de patologia como pode ser inferida a partir deles" (Plouffe, 2010, p.523).

\section{REFERÊNCIAS}

ALVES, Ernani Simas; PILOTTO, Mário (Ed.). Alô Ticoulat Guimarães: uma vida ilustre dedicada à medicina e ao ensino da psiquiatria. Curitiba: Fundação Santos Lima. 1994.

BERALDO, Renilson.

Ciência e associativismo médico: medicina legal e psiquiatria na terra dos pinheirais (1930-1941). Dissertação (Mestrado em História das Ciências e da Saúde) - Casa de Oswaldo Cruz/Fiocruz, Rio de Janeiro. 2016.

\section{CEDOC/G}

Centro de Documentação e Memória de Guarapuava. Processo n.951.2.3865, Juízo de Direito da Comarca de Guarapuava, caixa 209, 109 p. Universidade Estadual do Centro-Oeste, Paraná. 1951.

\section{CEDOC/G.}

Centro de Documentação e Memória de Guarapuava. Processo n.950.2.3776, Juízo de Direito da Comarca de Guarapuava, caixa 204, 30 p. Universidade Estadual do Centro-Oeste, Paraná. 1950.

COSTA, Iseu Affonso da; LIMA, Eduardo Corrêa (Ed.).

O ensino da medicina na Universidade Federal do Paraná. Curitiba: Editora da UFPR. 2007.
ERASO, Yolanda. Biotypology, endocrinology, and sterilization: the practice of eugenics in the treatment of Argentinian women during the 1930s. Bulletin of the History of Medicine, v.8, n.4, p.793-822. 2007.

GUIMARÃES, Alô Ticoulat.

A ciência psiquiátrica, seu mérito, sua evolução e suas conquistas no terreno da clínica e da terapêutica. Revista Médica do Paraná, ano 7, n.3, p.105-131, Biblioteca Pública do Paraná, Divisão de Documentação Paranaense (Curitiba-PR). 1938.

LIMA, Adriana de Alvarenga; HOLANDA, Adriano Furtado.

"O Dr. Alô falou para não contrariar": a consolidação da psiquiatria no Paraná na primeira metade do século XX. Estudos e Pesquisas em Psicologia, v.11, n.1, p.353-368. 2011.

MIRANDA, Marisa A.

La biotipología en el pronatalismo argentino (1930-1983). Asclepio, v.57, n.1, p.189-218. 2005.

OUYAMA, Maurício N.

Uma máquina de curar: o hospício Nossa Senhora da Luz em Curitiba e a formação da tecnologia asilar (final do século XIX e início do XX). Tese 
(Doutorado em História) - Universidade Federal do Paraná, Curitiba. 2006.

PLOUFFE, William C.

Kretschmer, Erst: physique and character. In: Cullen, Francis T.; Wilcox, Pamela (Ed.). Encyclopedia of criminological theory. University of Cincinnati: Sage Publications. p.521-524. 2010.

RINKE, Stefan.

Alemanha e Brasil, 1870-1945: uma relação entre espaços. História, Ciências, Saúde - Manguinhos, v.21, n.1, p.1-17. 2014.

SIQUEIRA, Márcia Dalledone (Ed.). Associação Médica do Paraná: 60 anos de história. Curitiba: AMP. 1993.

STERN, Alexandra Minna.

From mestizophilia to biotypology: racialization and science in Mexico. In: Appelbaum, Nancy P.; MacPherson, Anne S.; Rosemblatt, Karin Alejandra (Ed.). Race and nation in modern Latin American. Chapel Hill: The University of North Carolina Press. p.187-210. 2003.
VALLEJO, Gustavo.

El ojo de poder en el espacio del saber: los institutos de biotipología. Asclepio, v.56, n.1, p.219-244. 2004

VALLEJO, Gustavo; MIRANDA, Marisa. Los saberes del poder: eugenesia y biotipología en la Argentina del siglo XX. Revista de Indias, v.64, n.23, p.425-444. 2004.

VIMIEIRO-GOMES, Ana Carolina.

A emergência da biotipologia no Brasil: medir e classificar a morfologia, a fisiologia e o temperamento do brasileiro na década de 1930. Boletim do Museu Paraense Emílio Goeldi, Ciências Humanas, v.7, n.3, p.705-719. 2012.

WADI, Yonissa Marmitt (Ed.). Instituições de assistência psiquiátrica do estado do Paraná: inventário. Guarapuava: Unicentro. 2012.

WITTIG, Ehrenfried Othmar (Ed.).

Contribuição à história da medicina no Paraná: especialidades, hospitais, entidades. Curitiba: M.5 Gráficas e Editora. 2011.

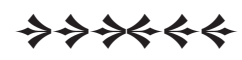




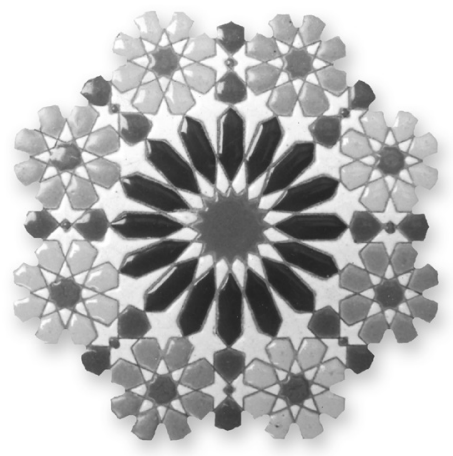

